The oxyhaemoglobin unloading characteristics of many animals, including terrestrial amphibians, provide oxygen to the tissues at higher partial pressures than does plasma. The most critical factors in the survival of erythrocyteless animals are likely to be the minimum oxygen tension (concentration) requirements of sensitive tissues, such as kidney or brain, and other erythrocyte functions such as $\mathrm{CO}_{2}$ transport and acid-base balance.

This study was supported in part by grants from the National Institute of Arthritis and Metabolic Diseases, US National Institutes of Health, and the US National Science Foundation. Joseph A. Grasso is the recipient of a development career award from the US National Hoart Institute.

Joseph A. Grasso

David C. Shephari

Department of Anatomy,

Case Western Reserve Üniversity,

Cleveland, Ohio.

Received March 11; revised April 25, 1968.

${ }^{2}$ Ruud, J. T., Nature, 178, 848 (1954).

${ }^{2}$ de Graaf, A. R., J. Exp. Biol., 34, 173 (1957)

${ }^{8}$ Ewer, D. W., Nature, 183, 271 (1959).

‘ Nicloux, M., CR Soc. Biol., 88, 1328 (1923).

'Serfaty, A., and Guetal, J., CR Soc. Biol.,137, 154 (1943).

- Flores, G., and Frieden, E., Scienee, 159, 101 (1968).

? Jordan, H. E., and Speidel, C., Amer. J. Anat., 46, 55 (1930).

${ }^{5}$ Grasso, J. A., and Woodard, J. W., J. Cell Biol., 31, 279 (1986).

- Rugh, R., Experimental Embryology, 49 (Burgess, Minneapolis, Minn., 1848).

${ }^{10}$ Bloom, W., Anat. Rec., 69, 99 (1937).

${ }^{12}$ Bloom, W., and Fawcett, D., $A$ Textbook of Histology, ninth ed., 207 (Saunders, Philadelphia, Pa., 1968).

${ }^{18}$ Czopèk, J., Copeia, No. 2, 91 (1959).

${ }^{13}$ Foxon, G. E. H., in Physiology of the Amphibia (edit. by J. A. Moore), 151 (Academic Press, New York, 1964).

${ }^{14}$ Krogh, A., Comparative Physiology of Respiratory Mechanisms (Univ. of Pennsylvania Press, 1959).

${ }^{15}$ Prosser, C. L., and Brown, F. A., Comparative Animal Physiology, 153 (Saunders Philadelphia, 1961).

\section{Opposite Hand Preferences in Two Sense-modalities}

HAND preferences have been recorded for 137 of the 150 monkeys used in behaviour experiments during 1958 to 1968. Eighty-seven of the 137 monkeys, however, were trained to make discriminations only in one sensemodality, or else were insufficiently assessed for hand preferences in two modalities. The following conditions obtain for all the remaining fifty monkeys: (1) no account was taken of an animal's first discrimination task (for which hand preferences tend to be atypical) unless the learning score exceeded five hundred trials; (2) treating the first task as described, discriminations were learnt at least twice in each of two sense-modalities (by thirty. nine monkeys through vision and touch, by eleven through vision and hearing); (3) hand preferences were systematically assessed during criterion performance on at least four training periods, distributed as described. Of the fifty monkeys adequately assessed in two sense-modalities thirty-oight preferred the same hand in both modalities, and (discounting tho first task) eight changed preference within one or both modalities. The remaining four animals (that is, 8 per cent) showed regular alternations of preferences with change of modality from touch to vision. These alternations were to some extent transiont in two, but have persisted unchanged in the other two monkeys.

Table 1 contains information about these monkeys. All four were purchased from the same source, but only Nos. 133 and 136 arrived in the same batch. All four were first trained on a tactile task (a simple shape or roughness discrimination task given in the dark). Animals 70 and 141 continuod with eight and nine additional tactile tasks (in the dark) before visual training (in the light) began. Animals 133 and 136 were trained alternately in the dark and light for their first five and seven tasks, respectively, before undergoing consecutive tactile training followed by consecutive visual training. Animal 70 participated in the experiment of Ettlinger and Blakemore $^{1}$ on conditional learning in two sense-modalities; animals 133 and 136 in the experiment of Milner and Ettlinger (unpublished observations) on cross-modal transfor of serial reversal learning; and animal 141 in the experiment of Blakemore and Ettlinger ${ }^{2}$ on cross-modal Iearning set formation. (We cannot, on our evidence, be certain that the opposite preferences should be related to visual/tactile learning, as contrasted with performance in the light/dark, as no tactile discriminations were given in the light.)

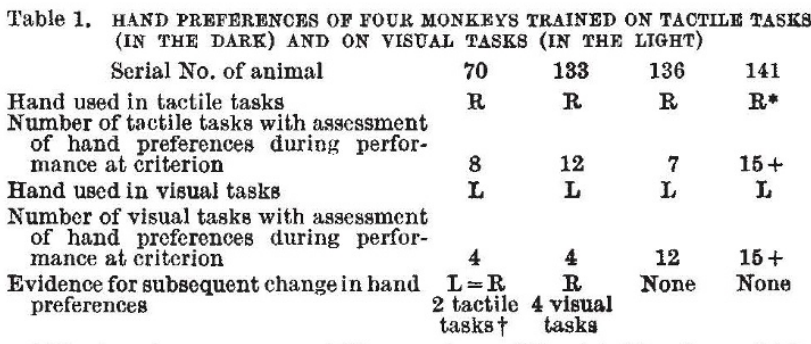
* Hand preferences represent 90 per cent use of the stated hand over thirty
(or occasionally fewer) trials during performance at criterion. The stated hand was always used to push the test-object and to gain the food reward, excep during tactile training in the case of animal 141: the right hand was used to palpate and push the test objects, but on most trials the left hand was used o gain the food reward.

Subsequent testing on one tactile and one visual task showed use of the right hand for the former, and of the left hand for the latter.

Gazzaniga ${ }^{3}$ has reported that visual learning can take place exclusively in the right hemisphere of monkoys, even if they naturally prefer the right hand, and equal use of both hands was secured during training by forced alternation every twenty or forty trials. This finding may have relevance to the fact that all our four monkeys showed a left-hand preference in visual training. As a corollary, the left hemisphere may be more closely concerned than the right with tactile learning in some monkeys. So far no experiment bearing directly on this possibility has been performed: monkeys can bo forced to use both hands alternately in making a tactile discrimination and then, after intervening transection of the cerebral commissures, can be tested with each hand individually. (In terms of a possible specialization of the left hemisphere for tactile and the right for visual learning in the monkey, the predominant incidence of a single hand preference needs explanation. Perhaps in most monkeys one sensory system is able to "capture" the preferred hand during infancy to an extent that it cannot thereafter become non-preferred even with the inflow changed to another sense-modality.) Whether or not our new and unexpected finding of opposite preferences in two sense-modalities can be interpreted in this way, it underlines: (1) the relative independence of the neural systems mediating visual and tactile learning in the monkey (or, possibly, performance in the light and dark); (2) the importance of the afferent, as distinct from the efferent, systems in determining hand preferences (as assessed by us) in the monkey.

This work was supported by the Mcdical Research Council.

G. EitTLinger

C. B. Blakemore

Institute of Psychiatry,

A. D. Miliner

London.

Received April 29, 1968.

1 Ettlinger, G., and Blakemore, C. B., Nature, 210, 117 (1966).

"Blakemore, C. B., and Ettlinger, G., J. Physiol., 196, 127P (1968).

${ }^{3}$ Gazzaniga, M. S., Exp. Neurol., 8, 14 (1963). 